\title{
Advances in Human Pluripotent Stem Cells for Regenerative Medicine and Drug Discovery
}

\section{Yan Li' ${ }^{1}$ and Shang-Tian Yang ${ }^{2 *}$}

${ }^{1}$ Department of Chemical and Biomedical Engineering, FAMU-FSU College of Engineering, Florida State University, USA ${ }^{2}$ William G Lowrie Department of Chemical and Biomolecular Engineering, The Ohio State University, USA

\section{Introduction}

TThe emerging Human Pluripotent Stem Cell (hPSC) technology brings many excitements for regenerative medicine and drug discovery [1]. Rapid advancements in hPSCs have been made in the past several years, including defined culture systems, procedures of directed differentiation, the demonstration of hPSC applications in drug screening, the establishment of various disease models, and the evaluation of therapeutic potential in treating incurable diseases through transplantation. This article highlights recent advancements in these areas and the current challenges for clinical applications based on hPSC technology.

\section{hPSCs for Drug Discovery and Disease Modeling}

hPSCs can provide a large amount of physiologically relevant human cells for drug screening [2]. The traditional models using cell lines and animals cannot fully recapitulate the human cell function. During drug discovery, about $90 \%$ of drug candidates cannot reach the stage of clinical trials due to the side effects and efficacy issues [3]. The derivation of hPSCs, especially Induced Pluripotent Stem Cells (iPSCs) from specific patients, opens a new era for disease modeling and drug discovery. Since the derivation of motor neurons from iPSCs of an 82year old patient with a familial form of Amyotrophic Lateral Sclerosis $(A L S)$, numerous types of neurological diseases and heart diseases have been modeled through the iPSCs [4]. For examples, iPSC-derived dopaminergic neurons have been used to evaluate 44 compounds that have demonstrated therapeutic effects in rodent models while only 16 showed significant neuroprotection effects using disease-relevant human cells [5]. A library of iPSC-derived cardiomyocytes from patients with various cardiac disorders (e.g. long QT syndrome, familial hypotrophic cardiomyopathy, and familial dilated cardiomyopathy) has been established [6]. The disease-specific cardiomyocytes demonstrated the increased susceptibility to cardiotoxic drugs that were not observed from the cells derived from healthy donors. These studies demonstrated the importance of using disease-relevant human cells for drug discovery, which offers a huge economic benefit to identify the drug candidates.

\section{hPSCs for Regenerative Medicine}

While the use of hPSC-derived cells for regenerative medicine has more hurdles compared to drug discovery due to the tumorigenecity and immunogenecity, the attractive unlimited cells of human source motivate the exploration of hPSCs for regenerative medicine [7]. The use of oligodendrocyte progenitors in spinal cord injury models and the retinal pigment epithelial cells for treating macular degenerations have been attempted in clinical trials [8]. The therapeutic potentials of hPSC derivatives, however, still require tremendous work and numerous preclinical studies. Transplantation of midbrain dopamine neurons derived from hPSCs showed long-term engraftment and behavior improvement in Parkinson's disease models using mice, rats, and monkeys as testing species [9]. The integration of hPSCderived cortical neurons with in vivo mouse brain circuits showed the developmental connectivity for brain repair [10]. HPSC-derived cells also provide novel sources for tissue engineering studies. iPSC-derived cardiac progenitor cells have been used to repopulate the decellularized heart scaffolds and showed the response to $\beta$-adrenergic agonist isoproterenol and displayed normal electrophysiology of heart tissue [11]. The formation of 3-Dimentional (3-D) liver bud by co-culturing iPSC-derived hepatic endoderm cells with human mesenchymal stem cells and human umbilical vein endothelial cells regenerated vascularized and metabolically active human liver in vivo [12]. All these studies demonstrated the therapeutic potential of hPSCs in regenerative medicine.

\section{hPSC Expansion Systems}

To fulfill the potential of hPSCs, efficient expansion and differentiation systems are required. The culture systems of hPSCs have evolved from feeder culture to feeder-free defined culture systems through the development of defined media, defined substrates, and controlled environmental cues for self-renewal [13-16]. In the absence of serum albumin and $\beta$-mercaptoethanol, eight essential components of hPSC growth media (i.e. E8 medium) were identified [17]. The defined substrates include the specific laminin isoforms, vitronectin peptides, and synthetic polymers such as Poly [2-(Methacryloyloxy) Ethyl Dimethyl-(3-Sulfopropyl) Ammonium Hydroxide] (PMEDSAH) $[18,19]$. Environmentally, the biomechanical properties of extracellular substrates and biochemical molecules (e.g. $\mathrm{O}_{2}$, small molecules to alter the metabolism) also were found as potent regulators for hPSC expansion [20-22]. To understand the factors leading to the heterogeneity of hPSCs and the cellular responses to the culture condition change, a high-throughput fingerprinting platform has been established recently to control cell fate [23].

Recent advances also emphasize the desire for large-scale expansion by using microcarrier-based (or scaffold-based) cultures and 3-D aggregate suspension cultures [20,24-27]. Both culture systems can be realized in bioreactors and have good scale-up potential. While microcarrier-based cultures have been shown to support hPSC expansion, their use for large-scale generation of differentiated cells has not been well studied [28]. Efforts are also directed to simplifying the coating of microcarriers and using defined media in the systems. For 3-D aggregate cultures, similarly, xeno-free culture components and aggregate size control have also been evaluated to better understand the characteristics and effects of the aggregate cultures [29].

*Corresponding author: Shang-Tian Yang, William G Lowrie Department of Chemical and Biomolecular Engineering, The Ohio State University, USA, Tel: 614292-6611; Fax: 614-292-3769; E-mail: yang.15@osu.edu

Received February 10, 2013; Accepted February 12, 2014; Published February 15,2014

Citation: Li Y, Yang ST (2014) Advances in Human Pluripotent Stem Cells for Regenerative Medicine and Drug Discovery. J Tissue Sci Eng 5: e127. doi:10.4172/2157-7552.1000e127

Copyright: (c) $2014 \mathrm{Li} \mathrm{Y}$, et al. This is an open-access article distributed under the terms of the Creative Commons Attribution License, which permits unrestricted use, distribution, and reproduction in any medium, provided the original author and source are credited. 
Thermoresponsive culture systems were also developed to ease the dissociation needs of hPSCs and enable the cell passaging in $3-\mathrm{D}$ hydrogel-based systems [30,31]. Based on the phase transition behavior of the Poly(N-Isopropylacrylamide)-Co-Poly(Ethylene Glycol) (PNIPAAm-PEG) hydrogel from a liquid to a solid gel as the temperature is increased, hPSCs can be rapidly encapsulated and retrieved, which enabled the 20-fold expansion during 4-5 days and the maintenance of the lineage-specific differentiation potential $[30,32]$.

\section{hPSC Differentiation into Specific Lineages}

The efficiency of the differentiation into specific lineages has improved significantly in recent years by modulating the developmental pathways rather than spontaneous differentiation. For example, the purity of cardiomyocytes derived from hPSCs has increased from less than $10 \%$ to $90 \%$ by temporally modulating Wnt, Activin/Nodal, and Bone Morphogenetic Protein (BMP) signaling during cardiac lineage commitments [33-35]. The differentiation of various types of neurons has also been significantly improved with the inhibition of dual SMAD signaling, the inhibition or activation of Wnt signaling, and the activation of sonic hedgehog pathway $[9,36]$. The protocols for generating specified forebrain interneurons, midbrain dopamine neurons, and the 3-D structures containing hindbrain regions have been developed recently to obtain not only the purified cells but also the complex 3-D organoids [9,36-38]. The differentiation into other lineages, such as pancreatic progenitor cells, hepatocytes, and hematopoietic cells, have also been demonstrated at high purities $[8,39]$.

\section{hPSC-Derived Cell Maturation}

To date, hPSC-derived cells are still immature and more resemble fetal tissues. Numerous efforts are underway to enhance the maturation of the differentiated cells from hPSCs. While high-purity of neural progenitor cells have been derived from hPSCs, little has been done to derive functional neuronal subtypes which can form synapses and display the high-frequency trains of action potentials and other mature electrophysiology [40]. The maturation of hPSC-derived forebrain interneurons required 7 months which mimicked endogenous human neural development, while acceleration of the development will facilitate the hPSC applications [36]. Maturation study of hPSCderived cardiomyocytes has been ongoing using various strategies rather than simple extending the culture time. Several approaches such as using 3-D scaffolds to create biomimetic cardiac wires, electrical stimulation, or stimulating adult cell energy metabolism have been investigated to improve cardiac cell maturation [41-45]. The initial success demonstrated the increased sensitivity to various drugs, including L-type $\mathrm{Ca}^{2+}$ channel blockers, Human Ether-a-go-go-Related Gene (hERG) $\mathrm{K}^{+}$channel blockers, and anti-arrhythmic drugs $[42,44]$. Additional novel strategies to promote differentiation and maturation of hPSC-derived cardiomyocytes are highly desirable and should be explored.

\section{Conclusions and Perspectives}

With the significant improvements in hPSC expansion and differentiation, more efforts are devoted to improving the function and maturation of hPSC-derived cells given the unique developmental potential of hPSCs. In this regard, the 3-D culture systems and the organogenesis studies become critical approaches to recreate the complex structures of a small region in the human bodies by deriving and differentiating iPSCs from the patients with various diseases. For clinical applications, more attentions and efforts need to be focused on large-scale generation of differentiated cell types. Compared to the relatively simple expansion and self-renewal of undifferentiated stem cells, it is much more challenging to generate functional differentiated cells as each type of cells and tissues uses a unique developmental path in their maturation process. Overall, in order to accelerate the applications of hPSCs it will require multiple advances in various fields including biology, chemistry, engineering, and material science.

\section{Acknowledgements}

Support from the National Science Foundation (grant No.1342192 to Y. Li) is acknowledged.

\section{References}

1. Robinton DA, Daley GQ (2012) The promise of induced pluripotent stem cells in research and therapy. Nature 481: 295-305.

2. Engle SJ, Puppala D (2013) Integrating human pluripotent stem cells into drug development. Cell Stem Cell 12: 669-677.

3. Grskovic M, Javaherian A, Strulovici B, Daley GQ (2011) Induced pluripotent stem cells--opportunities for disease modelling and drug discovery. Nat Rev Drug Discov 10: 915-929

4. Dimos JT, Rodolfa KT, Niakan KK, Weisenthal LM, Mitsumoto H, et al. (2008) Induced pluripotent stem cells generated from patients with ALS can be differentiated into motor neurons. Science 321: 1218-1221.

5. Peng J, Liu Q, Rao MS, Zeng X (2013) Using human pluripotent stem cellderived dopaminergic neurons to evaluate candidate Parkinson's disease therapeutic agents in MPP+ and rotenone models. J Biomol Screen 18: $522-$ 533.

6. Liang P, Lan F, Lee AS, Gong T, Sanchez-Freire V, et al. (2013) Drug screening using a library of human induced pluripotent stem cell-derived cardiomyocytes reveals disease-specific patterns of cardiotoxicity. Circulation 127: 1677-1691.

7. Wu SM, Hochedlinger K (2011) Harnessing the potential of induced pluripotent stem cells for regenerative medicine. Nat Cell Biol 13: 497-505.

8. Tabar V, Studer L (2014) Pluripotent stem cells in regenerative medicine: challenges and recent progress. Nat Rev Genet 15: 82-92.

9. Kriks S, Shim JW, Piao J, Ganat YM, Wakeman DR, et al. (2011) Dopamine neurons derived from human ES cells efficiently engraft in animal models of Parkinson's disease. Nature 480: 547-551.

10. Espuny-Camacho I, Michelsen KA, Gall D, Linaro D, Hasche A, et al. (2013) Pyramidal neurons derived from human pluripotent stem cells integrate efficiently into mouse brain circuits in vivo. Neuron 77: 440-456

11. Lu TY, Lin B, Kim J, Sullivan M, Tobita K, et al. (2013) Repopulation of decellularized mouse heart with human induced pluripotent stem cell-derived cardiovascular progenitor cells. Nat Commun 4: 2307.

12. Takebe T, Sekine K, Enomura M, Koike H, Kimura M, et al. (2013) Vascularized and functional human liver from an iPSC-derived organ bud transplant. Nature 499:481-484.

13. Chen KG, Mallon BS2, McKay RD3, Robey PG4 (2014) Human pluripotent stem cell culture: considerations for maintenance, expansion, and therapeutics. Cell Stem Cell 14: 13-26.

14. Hazeltine LB, Selekman JA, Palecek SP (2013) Engineering the human pluripotent stem cell microenvironment to direct cell fate. Biotechnol Adv 31 1002-1019.

15. Li Y, Gautam A, Yang J, Qiu L, Melkoumian Z, et al. (2013) Differentiation of oligodendrocyte progenitor cells from human embryonic stem cells on vitronectin-derived synthetic peptide acrylate surface. Stem Cells Dev 22 1497-1505.

16. Li Y, Powell S, Brunette E, Lebkowski J, Mandalam R (2005) Expansion of human embryonic stem cells in defined serum-free medium devoid of animalderived products. Biotechnol Bioeng 91: 688-698.

17. Chen G, Gulbranson DR, Hou Z, Bolin JM, Ruotti V, et al. (2011) Chemically defined conditions for human iPSC derivation and culture. Nat Methods 8: 424429 .

18. Villa-Diaz LG, Ross AM, Lahann J, Krebsbach PH (2013) Concise review: The evolution of human pluripotent stem cell culture: from feeder cells to synthetic coatings. Stem Cells 31: 1-7. 
Citation: Li Y, Yang ST (2014) Advances in Human Pluripotent Stem Cells for Regenerative Medicine and Drug Discovery. J Tissue Sci Eng 5: e127. doi:10.4172/2157-7552.1000e127

Page 3 of 3

19. Melkoumian Z, Weber JL, Weber DM, Fadeev AG, Zhou Y, et al. (2010) Synthetic peptide-acrylate surfaces for long-term self-renewal and cardiomyocyte differentiation of human embryonic stem cells. Nat Biotechnol 28: $606-610$.

20. Sart S, Agathos SN, Li Y (2013) Engineering stem cell fate with biochemical and biomechanical properties of microcarriers. Biotechnol Prog 29: 1354-1366.

21. Sart S, Agathos SN, Li Y (2014) Process engineering of stem cell metabolism for large scale expansion and differentiation in bioreactors. Biochem Eng J 84 74-82.

22. Sun Y, Villa-Diaz LG, Lam RH, Chen W, Krebsbach PH, et al. (2012) Mechanics regulates fate decisions of human embryonic stem cells. PLoS One 7: e37178.

23. Nazareth EJ, Ostblom JE, Lücker PB, Shukla S, Alvarez MM, et al. (2013) Highthroughput fingerprinting of human pluripotent stem cell fate responses and lineage bias. Nat Methods 10: 1225-1231.

24. Serra M, Brito C, Correia C, Alves PM (2012) Process engineering of human pluripotent stem cells for clinical application. Trends Biotechnol 30: 350-359.

25. Abbasalizadeh S, Baharvand $H$ (2013) Technological progress and challenges towards cGMP manufacturing of human pluripotent stem cells based therapeutic products for allogeneic and autologous cell therapies. Biotechnol Adv 31: 1600-1623.

26. Liu N, Zang R, Yang ST, Li Y (2014) Stem cell engineering in bioreactors for large scale bioprocessing. Eng Life Sci 14: 4-15.

27. Liu M, Li Y, Yang ST (2014) Expansion of human amniotic fluid stem cells in 3-Dimensional fibrous scaffolds in stirred bioreactors. Biochem Eng J 82: 7180.

28. Chen AK, Reuveny S, Oh SK (2013) Application of human mesenchymal and pluripotent stem cell microcarrier cultures in cellular therapy: achievements and future direction. Biotechnol Adv 31: 1032-1046.

29. Wang Y, Chou BK, Dowey S, He C, Gerecht S, et al. (2013) Scalable expansion of human induced pluripotent stem cells in the defined xeno-free E8 medium under adherent and suspension culture conditions. Stem Cell Res 11: 11031116.

30. Lei Y, Schaffer DV (2013) A fully defined and scalable 3D culture system for human pluripotent stem cell expansion and differentiation. Proc Natl Acad Sci U S A 110: E5039-5048.

31. Zhang R, Mjoseng HK, Hoeve MA, Bauer NG, Pells S, et al. (2013) A thermoresponsive and chemically defined hydrogel for long-term culture of human embryonic stem cells. Nat Commun 4: 1335.
32. McDevitt TC (2013) Scalable culture of human pluripotent stem cells in 3D. Proc Natl Acad Sci U S A 110: 20852-20853.

33. Lian X, Hsiao C, Wilson G, Zhu K, Hazeltine LB, et al. (2012) Robus cardiomyocyte differentiation from human pluripotent stem cells via temporal modulation of canonical Wnt signaling. Proc Natl Acad Sci U S A 109: E18481857.

34. Xu C (2012) Differentiation and enrichment of cardiomyocytes from human pluripotent stem cells. J Mol Cell Cardiol 52: 1203-1212.

35. Xu C, Police S, Hassanipour M, Li Y, Chen Y, et al. (2011) Efficient generation and cryopreservation of cardiomyocytes derived from human embryonic stem cells. Regen Med 6: 53-66.

36. Nicholas CR, Chen J, Tang Y, Southwell DG, Chalmers N, et al. (2013) Functional maturation of hPSC-derived forebrain interneurons requires an extended timeline and mimics human neural development. Cell Stem Cell 12 . 573-586.

37. Lancaster MA, Renner M, Martin CA, Wenzel D, Bicknell LS, et al. (2013) Cerebral organoids model human brain development and microcephaly. Nature 501: 373-379.

38. Li Y, Liu M, Yan Y, Yang S-T (2014) Neural differentiation from pluripotent stem cells: The role of natural and synthetic extracellular matrix. World J Stem Cells 6: $11-23$

39. Li Y, Liu M, Yang ST (2014) Dendritic cells derived from pluripotent stem cells: potential of large scale production. World J Stem Cells 6: 1-10.

40. Yu DX, Marchetto MC, Gage FH (2013) Therapeutic translation of iPSCs for treating neurological disease. Cell Stem Cell 12: 678-688.

41. Chen A, Lee E, Tu R, Santiago K, Grosberg A, et al. (2014) Integrated platform for functional monitoring of biomimetic heart sheets derived from human pluripotent stem cells. Biomaterials 35: 675-683.

42. Nunes SS, Miklas JW, Liu J, Aschar-Sobbi R, Xiao Y, et al. (2013) Biowire: a platform for maturation of human pluripotent stem cell-derived cardiomyocytes. Nat Methods 10: 781-787.

43. Kim C, Wong J, Wen J, Wang S, Wang C, et al. (2013) Studying arrhythmogenic right ventricular dysplasia with patient-specific iPSCs. Nature 494: 105-110.

44. Thavandiran N1, Dubois N, Mikryukov A, Massé S, Beca B, et al. (2013) Design and formulation of functional pluripotent stem cell-derived cardiac microtissues. Proc Natl Acad Sci U S A 110: E4698-E4707.

45. Zhang D, Shadrin IY, Lam J, Xian HQ, Snodgrass HR, et al. (2013) Tissueengineered cardiac patch for advanced functional maturation of human ESCderived cardiomyocytes. Biomaterials 34: 5813-5820. 